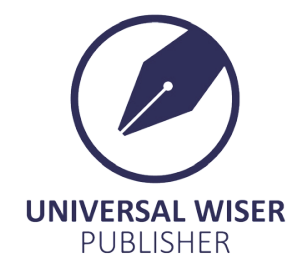

\title{
Informal Sector in India: Migration and Poverty Implications
}

\author{
Arup Mitra \\ South Asian University and Institute of Economic Growth, Delhi \\ E-mail: arup@iegindia.org
}

\begin{abstract}
For assessing the role of urbanization in reducing poverty this paper based on secondary datatries to examine the nature of relationship among urbanisation, migration and informal sector employment. Findings suggest that the informal sector also tends to attract migrants as the probability to get work opportunities in this sector could be high. Further, rural and urban poverty are inter-connected as rural to urban migration and informal sector employment and other state-specific characteristics are associated, though migration and urbanisation with its spill-over effects reduce both rural and urban poverty. Also,based onthe survey data for unincorporated enterprises, the paper examinesif the unorganized or informal manufacturing, trade and services have the potentiality to grow and contribute to the realization of the inclusive growth objective. The inter-sectoral linkages do not necessarily mean that productivity and wages improve in the informal sector if the units manage to receive business contract from the formal sector enterprises. In fact, a large body of the informal sector is seen to be unconnected to the formal sector and this independent segment is on the rise over time. Finally the paper argues for the introduction of an informal sector policy which may help reduce the welfare losses to labour employed at the lower rungs
\end{abstract}

Keywords: informal sector employment, urbanisation, ancillary, industry, contract

\section{Introduction}

Can urbanization reduce poverty by providing employment opportunities? This is a key question which has been bothering the researchers as well as the policy makers. One view is that in the face of inadequate industrialization of the work force the informal sector has grown rapidly and this being a repository of residual employment migrants do not benefit significantly and thus, rural poverty gets transferred to its urban counterpart ${ }^{[4]}$. However, an alternative view is that the informal sector holds prospects for upward mobility and thus, urbnanisation is associated with a decline in poverty. In the backdrop of this debate the present paper pursues a substantial analysis in the Indian context.

Various sources are used to draw the database of the study. The secondary data sources include informal sector enterprises surveys of the government. These collect and offer information on types of enterprises where persons usually employed in non-agriculture and AGEGC sectors information was collected on the types of enterprises, found work. In other words, these surveys were carried out for the non-agriculture and AGEC enterprises which employed persons on the basis of usual principal-cum-secondary status, as identified by the NSSO's employment and unemployment survey 2009-10, and more recently by the National Statistical Office's Periodic Labour Force Survey (2017-18). Additionally, NSSO's special surveys on unorganised/unicorporated non-agricultural enterprises (2010-11) have also been used. Population census (2011) and the NSSO's migration survey (2006-07) data are analysed to understand extensively the relationship among different variables. Further, based on the qualitative survey of home based workers the paper focuses on the vulnerability of workers in terms of their bargaining power. The methodology is based on factor analysis and other econometric analysis. [See the appendix]

\section{Review of studies}

In the context of developing countries, particularly India, informal sector is an important category that cuts acrossalmost the entire range of activities in the three tiers of the economy, from agriculture to manufacturing and fields of the services arena. In spite of difficulties involved in defining the term, it has been used extensively, particularly in the 
empirical literature ${ }^{[18]}$. The thrust of research has been on the size and contribution of the informal sector in providing sources of livelihood: as low income households cannot afford to remain unemployed for long, we have the phenomenon of the 'working poor'. As Habib-Mintz ${ }^{[8]}$ wrote, the term first entered academic discourse during the 1970s; subsequently it evolved conceptually through several distinct phases starting with neoliberal to reformist and then structuralist ideology. Since the seventies, governments and individual researchers have felt the compulsion to collect information on the informal sector and unsecured employment, particularly in order to reflect upon the linkages between economic growth and standards of living. Though the development economics literature in the early years ${ }^{[22]}$ suggested that the emergence of the informal sector is only a transitory phenomenon its persistence and considerable overlaps with poverty have been noted widely. ${ }^{[22]}$

First proposed by Todaro ${ }^{[22]}$, as the concept of informal sector got increasingly integrated into the literature in development economics, the need for defining its characteristics and quantitative parameters was felt. These were envisaged in terms of the smallness of the size of the operating unit, poor level of technology, perfect competition prevailing in the factor and product markets both, the lack of protection by the government to units/workers, the lack of unionization of the work force ${ }^{[7,17]}$. However, a more pragmatic working definition was required, and for this usually the size and/or the ownership criterion is considered ${ }^{[11]}$. A number of studies in the past noted that more than half of the city work force is located in the urban informal sector ${ }^{[17,11]}$. Besides, a large majority of the informal sector workers were employed in the low productivity segment of the services sector.

As Charmes ${ }^{[2]}$ tacitly points out, several debates paved the way for the international definition, in 1993, of the informal sector, and in 2003, of informal employment: the informal economy is finally a means for conciliating the two concepts.However,informal sector employment is only a subset of informal employment ${ }^{[1,17,20]}$ as informal employment includes both informal sector employment and those engaged informally in the formal sector. Two contested issues of crucial importance to policy stand out within the literature: firstly, formal labour regulations as a cause of informal employment;secondly the so $\square$ called 'voluntary' informal employment ${ }^{[9]}$. In an attempt to avoid strict labour laws and reduce labour costs, firms have taken recourse to hire and fire practices,even as the fear of losing revenue have led state governments to extendindirect support to these practices ${ }^{[23]}$. Undermining the objectives of social justice, the shift towards informalisation in high growth industries received state support to facilitate growth in profits.

The effects of the above patterns are manifested in terms of considerable overlaps between poverty and informal employment ${ }^{[14]}$. Barnes ${ }^{[1]}$ urged that growth in India has been accompanied by a major shift towards the employment of wage workers in informal sector enterprises and the concentration of informal wage workers in large, formal sector enterprises. Srivastava ${ }^{[21]}$ focused on the increasing informalisation and flexibilisation of labour. This is in sharp contrast to the view emphasizing the centrality of self-employment and petty-commodity production units in the context of the Indian labour market. Sastry ${ }^{[20]}$ based on the NSS data, (1999-00), showed that the incidence of poverty and the intensity of poverty among households sustaining on employment in the informal sector were higher in the urban areas in comparison to the rural areas. Also, the incidence and intensity of poverty among those working in the informal sector are found to be higher than that among the general population in the urban areas.These patterns of growing linkages between urban poverty and the increasing scope of informal employment has impacted on earlier assumptions that urbanization was expected to yield improved work opportunities and standards of living; these indications are far from clear for the 2000s.

A brief review of the several studies on informal sector in the Indian context in last twenty years or so may be seen in Das ${ }^{[5]}$. However, the present paper goes a step further keeping in view the important role the informal sector plays in providing sources of livelihood,and it delineates recent changes that are observable in relation to contractualisation and ancillarisationimpacting on work practices and performance of the informal workers. Reflecting on linkages between the formal and informal sectors, it explores if there exist sub-sectors that have the potentiality to grow and contribute to the realization of the country's pro-poor growth objective.Also, the paper highlights the paradox of rising work consignments accompanied by meager earnings, explainable through sub-contracting practices that have become common.

\section{Empirical analysis: broad patterns}

Most of the agricultural sector is located within the arena of the informal sector (Table 1). But other non-agricultural activities also comprise a large informal segment. Skill and educational level of the individuals determine if they will be operating within the formal or the informal sector.Workers with poor human, physical and financial capital get residually absorbed in own account enterprises and other small units. As far as mobility is concerned some of them remain perpetually within the informal sector though they may be experiencing upward mobility within the sector. With better quality education,improved accessibility to market information, credit facilities and technological know-how the scale of operation 
may expand. Thus, it may be possible for the units to graduate to the formal sector. However, it is important to consider the cost associated with the graduation process.For example, with stringent registration procedure and the labour laws a unit may prefer to work in the informal sector rather than graduating to the formal sector ${ }^{[10]}$. Also, by remaining small in size a firm can take the advantage of the labour market flexibility prevailing in the informal sector. In these situations the informal sector units are not necessarily residual in nature or characterized by low productivity. They are rather expected to be technically efficient and highly competitive. The linkages between the informal and the formal economy, therefore, need to be understood in relation to the formal regulatory environment as pointed out by $\mathrm{Chen}^{[3]}$.

The incidence of informal sector employment is high both in the rural and urban areas. In addition to the agricultural activities even non-agriculture activities comprise avery large large proportion of workers in the informal segment in the ruralas well as urban areas.

Estimates of informal sector employment from NSS (2009-10)data are possibly not in synch with the realpicture because the definition there mainly comprises employment in the informal sector enterprises (proprietary and partnership enterprises). This excludes employees in the household sector, which by all counts, needs to be examined as an importantsegment of informal sector employment. Since employment in thehousehold sector is quite substantial, its exclusion tends to grossly underestimate the relative size of informal sector employment as reported by NSS 2009-10, presented here in Table 1. Further, because of its flexibility, household sectoris the 'preferred' site of entry into the labour force for a large section of women workers ${ }^{[12]}$, and its exclusion may have resulted in an underestimation of informal sector employment, particularly among the women workers. The size of the segment within informal employment comprising casual or short term contractual or irregular workers in the formal sector in addition to the informal sector workers,is indeed phenomenally large.

Table 1. Incidence of Informal Sector (\%): All-India (2009-10)

\begin{tabular}{ccccccc}
\hline \multirow{2}{*}{ Location } & \multicolumn{2}{c}{ Agricultural Activities } & \multicolumn{3}{c}{ Non-Agricultural Activities } \\
& Male & Female & Person & Male & Female & Person \\
\hline Rural Areas & 90.6 & 95.0 & 93.4 & 73.0 & 64.1 & 71.3 \\
Urban Areas & 88.3 & 97.7 & 92.5 & 68.3 & 60.1 & 66.9 \\
\hline
\end{tabular}

Source: Estimates Based on NSS Enterprise Survey Data, 2009-10.

In the Periodic LabourForce Survey (2017-18), for persons usually employed in non-agriculture and AGEGC[ Agricultural sector Excluding Growing of Crops, plant propagation, combined production of crops and animals without a specialized production of crops or animals are referred to as AGEGC sector [Agricultural sector Excluding Growing of Crops, plant propagation) in this Report.] sectors, information was collected regarding the types of enterprises in which they worked. Unincorporated enterprises owned by households, (i.e., proprietary and partnership enterprises, including informal producers' cooperatives) are largely considered as informal sector enterprises by the Government department[ According to the conceptual framework suggested by the 15th International Conference of Labour Statisticians, unincorporated enterprises owned by households, (i.e., proprietary and partnership enterprises including the informal producers' cooperatives) are largely considered as informal sector enterprises (p. 67, Periodic Labour Force Survey, 201718 published in May 2019).]. This data once again reiterates the vulnerability of a predominant segment of the labour force in India. The share of informal sector is estimated at 68.4 per cent among workers engaged as per the usual status (principal and subsidiary status) in the AGEGC and non-agriculture sectors: gender wise figures for this share being 71.1 and 54.8 percent for male and female workers respectively. Further, among regular wage/salaried employees in non-agricultural activities, 71.1 per cent had no written job contract - 72.3 percent among males and 66.8 per cent among females. Among regular wage/salaried employees in the non-agricultural activities, 54.2 per cent were not eligible for paid leave - 55.2 per cent among males and 50.4 per cent among females. Among regular wage/salaried employees in non-agricultural activities, 49.6 per cent were not eligible for any social security benefit - 49 per cent among males and 51.8 per cent among females. These figures reflect on the vulnerability of a large percentage of the work force in the Indian labour market.

\section{Inter-connections between migration, urban informal sector employment, poverty}

In this section we make an attempt to understand the dynamics of the informal sector by examining its relationship with a number of other demographic and labour market specific variables. As individuals residually employed in agriculture gravitate to the urban informal sector, this section posits a growing relationship between urban and rural poverty. Thus 
impelled even by the hope of finding employment in the urban informal sector, current patterns of migration allow for ways to connect rural and urban poverty. It may be hypothesized that the possibility to work within the informal sector may induce population movement from the rural to the urban space and thus, rural and urban poverty remain associated through migration and other characteristics defined by regional-level dynamics. Alternately migration and an increased urbanisation level may reduce rural and urban poverty, both due to the beneficial effects of urbanisation.

Results based on the factor analysis reveals that higher rural literacy raises the migration rate, moderately though (Table 2). The percentage of scheduled castes in the rural areas tends to induce out-migration rate, supporting the view that the disadvantaged sections move out to escape their poverty and vulnerability (factor 1 ). The most striking part is that rural and urban poverty both decline in relation to migration (see both factor 1 and factor 4) though this pattern is not very strong. As rural poor migrate to the urban areas their absorption within the urban informal sector brings in better livelihood opportunities in comparison to their pre-migration status. Thus, the migration process reflects on a decline in the incidence of poverty though in the Indian context such upward mobility is not seen as a prevalent phenomenon.

Both in the rural and urban areas the work participation rate is positively associated with migration (factor 2). This suggests that those in the labour market have a higher probability of migrating out, and subsequent to migration they are also more likely to continue in the job market instead of withdrawing. Further, states which are more urbanized than others are likely to experience these patterns, suggesting a positive impact of urbanization on job market and employment.

The results are also indicative of the fact that the socially backward groups are more likely to migrate due to the impact of push factors such as poverty. Also they may land up in the urban informal sector given the poor resource and human capital endowment. Variables such as migration, urban informal sector employment, and the incidence of scheduled caste (SC) population (representing lower social categories in terms of caste) in the urban and rural areas seem to have a positive association. This pattern is, however, accompanied by a decline in the poverty incidence in both the rural and urban areas, nominally though (factor 3). As the lower social categories are vulnerable in terms of the lack of cultivable land and other assets they are expected to have a higher propensity to migrate. However, given their poor human capital endowment they are not able to access jobs in the high productivity segment in the urban sector, captured in terms of a positive association between migration and urban informal sector employment. The only positive outcome of this phenomenon is that within the urban informal sector there are possibilities of improving the living standards, only to a limited extent though.

Turning to factor 4 it may be observed that urbanization takes the highest factor loading. Moreover it is positively associated with the percentage of the workforce engaged in non-household manufacturing and services, both in the rural and urban areas. Also, urbanization on the one hand and rural and urban poverty on the other are negatively associated. On the whole, one may infer that the urbanization process ushers in opportunities to accessing relatively higher jobs though such patterns are not strongly discernible in terms of the factor loadings.

In none of the significant factors the factor loadings of urbanization and urban informal sector employment both turn out to be high or moderate, simultaneously. Only one of the two variables is closer to unity in factor 3 or factor 4 while the other variables corresponds to insignificant coefficients. That the relationship between urbanization and informal sector employment is not strong is evident from these results. 
Table 2. Results from Factor Analysis

\begin{tabular}{ccccc}
\hline Variables & Factor 1 & Factor 2 & Factor 3 & Factor 4 \\
\hline MIGRATION & -0.114 & 0.181 & 0.229 & 0.140 \\
UINFORMAL & -0.157 & -0.10 & 0.603 & -0.025 \\
MIGR EMP MALE & 0.111 & 0.166 & -0.128 & 0.049 \\
RHHSIZE & 0.658 & -0.428 & -0.105 & -0.160 \\
RCHILD-WOMAN & 0.867 & -0.206 & -0.143 & -0.151 \\
RWFPR & -0.126 & 0.68 & -.079 & -0.102 \\
RLIT & -0.536 & 0.072 & -0.091 & 0.524 \\
RSC & -0.147 & -0.041 & 0.907 & -0.071 \\
ROTHERACTIVITIES & -0.141 & 0.042 & -0.152 & 0.864 \\
UHHSIZE & 0.494 & -0.773 & -0.029 & -0.075 \\
UCHILD-WOMAN & 0.836 & 0.041 & -0.179 & 0.032 \\
UWFPR & -0.0001 & 0.922 & -0.093 & 0.170 \\
ULIT & -0.437 & 0.288 & -0.251 & 0.212 \\
USC & -0.055 & -0.030 & 0.925 & -0.072 \\
RPOVERTY & -0.157 & 0.146 & -0129 & 0.436 \\
UPOVERTY & 0.119 & 0.174 & -0.119 & -0.213 \\
URBNISATION & 0.270 & -0.180 & -0.097 & -0.252 \\
Eigen Value & -0.024 & 0.143 & 0.003 & 0.867 \\
\% Explained & 5.43 & 2.97 & 2.18 & 1.60 \\
UOTHERACTIVITIES & 0.36 & 0.19 & 0.14 & 0.11 \\
\hline
\end{tabular}

No. of Observations $=35$.

Rural and Urban areas are represented in terms of the subscripts $\mathrm{R}$ and $\mathrm{U}$ respectively. Other variables are as follows: migration rate for the year 2007-08: MIGRATION; migration among males for employment: MIG EMP MALE; the proportion of informal sector employment to total employment in all non-agricultural activities in the urban areas for the year 2009-10: UINFORMAL; The ratio of children to women for the year 2011: CHILD-WOMAN; literacy rate for the year 2011: LIT; \% of scheduled caste population for the year 2011: SC; household size for

the year 2011: HHSIZE; work force participation rate for the year 2011: WFPR; \% of workforce engaged in other activities for the year 2011: OTHERACTIVITIES; poverty incidence for the year 2011-12: POVERTY; and \% urbanization from 2011 population census: URBNISATION Source: Authors' estimation based on NSSO and Population Census (2011) data.

\section{Performance of unorganised manufacturing, trade and services}

Given this background, the analysis may be pursued for some of the components within the informal or unorganised sector, e.g., unorganised manufacturing, trade and services, from the data on unincorporated enterprises in non-agricultural activities (National Sample Survey for the year 2010-11.)

Within the unorganised manufacturing and tertiary segment two components are perceptible: one, own account manufacturing enterprises and two, the establishments which hire workers from the labour market. The unorganised sector units across states are not found to be evenly distributed, which would suggest that states with higher urbanisation level, per capita income and industrialisation encourage the growth of the unorganised manufacturing units though there are certain exceptions: handicrafts, cottage industries and other home based activities provide major sources of livelihood in areas which stagnant in terms of growth, industrialisation and per capita income. Whether a similar pattern prevails in the unorganised trade and services components as well is an important question. Large trade and service enterprises may encourage small units to emerge and function within the domain of the informal sector, with a great deal of complimentary effects. We need to understand if the clusterisation of various activities takes place within the unorganised sector or alternately different unorganised sector activities unravel dynamics in relation to the organised or formal sector activities. For example, it may be logical to expect that business sub-contracting and ancillarisation would encourage organised and unorganised manufacturing to go hand in hand rather than unorganised manufacturing and unorganised trade-cumservices being inter-connected. Mukim ${ }^{[16]}$ analysed co-agglomeration patterns between formal and informal manufacturing enterprises in India, and studied the causes underlying these patterns, and the positive externalities, if any, on the entry of new firms. Similar dynamics might have existed pertaining to other activities such as trade and services.

The results from the factor analysis conducted on the proportion of units in various categories across states show certain striking patterns. First, the urban specific shares are the most dominant ones (urban own account enterprises in manufacturing, urban establishments in manufacturing, urban own account enterprises in trade, urban establishments in trade, urban own account enterprises in services and urban establishments in services). Second, next to the first in terms of significance a cluster is formed by the rural specific variables - rural own account enterprises in manufacturing, rural establishments in manufacturing, rural own account enterprises in trade, rural own account enterprises in services, and rural establishments in services. In other words, the urban specific variables which are strongly inter-connected explain 
most of the variations and next to them are the rural specific units which again form their own cluster (Table 3 ).

Table 3. Factor Analysis Results Based on the Distribution of Enterprises across States (2010-11)

\begin{tabular}{ccc}
\hline Variables & Factor1 & Factor2 \\
\hline OAEs in Rural Manufacturing & 0.3991 & 0.7786 \\
ESTs in Rural Manufacturing & 0.4275 & 0.6070 \\
OAEs in Urban Manufacturing & 0.7859 & 0.3061 \\
ESTs in Urban Manufacturing & 0.9199 & 0.2260 \\
OAEs in Rural Trade & 0.3499 & 0.8863 \\
ESTs in Rural Trade & 0.3545 & 0.4093 \\
OAEs in Urban Trade & 0.7924 & 0.5582 \\
ESTs in Urban Trade & 0.8569 & 0.3328 \\
OAEs in Rural Services & 0.3862 & 0.7900 \\
ESTs in Rural Services & 0.4081 & 0.6386 \\
OAEs in Urban Services & 0.806 & 0.484 \\
ESTs in Urban Services & 0.883 & 0.353 \\
Eigen Value & 9.65 & 1.1 \\
\hline
\end{tabular}

Source: Based on the Survey on Unincorporated Non-agricultural Enterprises (Excluding Construction) by NSS for the year 2010-11. See Mitra and Pandey (2015). OAEs represents own account enterprises and ESTs, establishments.

From the empirical analysis we noted that the unorganized manufacturing, trade and services show a strong association across regions. The fact that they are concentrated in relatively advanced states suggests that the growth dynamics influences all the three activities positively. It is understandable that higher levels of growth or per capita income, urbanization ratio and industrial growth can influence the performance of the small manufacturing and trade simultaneously as the small units might have been complementary to the large units. Though services may not be connected to manufacturing or trade directly studies have noted that higher incomes generate demand for new services which are supplied by the informal sector in the economy ${ }^{[19]}$.

In comparison to the own account enterprises, which account for a large majority of the units within the unorganised sector, the establishments are more employment generating. Labour per enterprise in the establishments is much greater than that in the own account manufacturing enterprises. Across the establishments, manufacturing is relatively more employment-intensive compared to trade and services. Across states, the rural areas show a positive correlation of around 0.89 between worker per establishment in manufacturing and that in trade. On the other hand, in the urban areas the positive association is seen between trade and services establishments. It may be inferred from this that the production dynamics running from manufacturing to trading requirements is evident in the rural areas while in the urban context income dynamics resulting in trading of goods and demand for services is prevalent. This may be taken to suggest that the rural areas with good connectivity between manufacturing and trade result in beneficial effects on livelihood, earnings and poverty. On the other hand, in the urban areas the linkage between trade and services does not necessarily imply an increase in earnings as the workers might have been engaged in the lower rungs of both the activities. In spite of an expansion in demand, the excess supplies of labour in relation to petty and menial jobs may not allow the earnings to rise significantly. In other words, the persistent nature of the urban informal sector and meagre earnings accruing to the workers in this sector are some of the possible outcomes. This however, does not mean that population flow from the rural to the cities may decelerate. Given the higher natural growth of population in the rural areas in comparison to the urban areas population mobility may still take place, particularly in the face of shrinking employment opportunities in the rural areas.

Employment and Wage in Unorganised Manufacturing, Trade and Services: Determinants ${ }^{[15]}$.

Employment elasticity which is defined as the proportionate change in employment due to proportionate change in value added has been estimated for each of these three activities in the unorganised or informal sector. The results show that the elasticity is almost unity in the case of establishments in unorganised manufacturing. Though trade and services are believed to be more labour intensive our findings are just the opposite, i.e., the elasticity is estimated at a much lower magnitude.

The elasticity of employment with respect to wage per worker reflects on the sensitivity employment in relation to wages. It is expected to be negative and our results also conform to this. For unorganised manufacturing and services it is estimated at 0.5 , implying that a one percent increase in wages can raise employment by half a percent. Though the absolute magnitude is higher than that in the organised manufacturing ${ }^{[6]}$, we may note that the wage rate in the unorganised manufacturing is much lower than that in the organised sector. Hence, any attempt to raise employment by offering lower wages can affect the wellbeing of the workers adversely. Labour laws are either not applicable or not strictly implemented 
in the case of the unorganised sector. Hence, the lack of safety net can only aggravate the living standards.

Labour productivity is an important determinant of wages. The elasticity of wages with respect to labour productivity turns out to be around 0.5 for unorganized trade and services. On the other hand, for the unorganized manufacturing it is even more than that. But given the fact that the productivity levels are much lower in the unorganised sector than the organised sector due to the lack capital and adoption of poor level of technology ${ }^{[6]}$, better level of living are not implied by greater wage-productivity nexus.

It has been widely argued that the unorganised sector units which work for the organised sector units are better-off as regularity of work consignments may result in lesser labour turnover and higher wages. As we incorporated the labour contract dummy to make a distinction between the units which have and which do not have any business contract from the formal sector units, the coefficient is not found to be statistically significant. We may, therefore, infer that not necessarily faster industrialisation leads to ancillarisation and growth in productive employment in the small units. Similarly linkages between large and small trading units do not ensure improvement in wages in the smaller units in the unorganised sector. However, in the case of services a positive association is indicated suggesting that the large units while getting their work done by the small units offer higher wages. Several new services which have emerged in the recent years as Rakshit ${ }^{[19]}$ points out, unravel linkages between the large and small units operating in two different sectors.

Certain results from the field survey conducted on the home based workers in Delhi in 2009 are cited here to emphasize some of the features of the informal sector [The author is grateful to Mayumi Murayama, Institute of Developing Economies, Japan for sharing her data set]. We could locate three types of activities: tailoring and embroidery, jewelry and packaging. Many of the workers belonged to the traditional weaver communities and their current employment involved weaving and stitching related work. Many of the households did not have any facility for storage of the raw materials like cotton.

Most of the workers received work consignments through contractors who were mediating between the shop keepers and these workers. Some of the products carried the brand names though others were sold without any brand. Supply of raw materials and collection of the final products both were carried out by the contractors. There was no shortage of work consignments. But the wage rate offered on a piece-rate basis was pitiably low in comparison to the amount of labour hours the workers had put in. The middlemen extracted a large sum at the expense of the workers. These observations reconfirm the fact that having a contract from the formal sector does not necessarily imply any improvement in the informal sector wages.

\section{Supply-push component within the informal sector}

The informal sector is often said to be growing independent of the formal sector. Hence, it is important to assess as to how much of the informal sector growth is connected through various linkages to the formal sector.

In order to estimate the supply-push component within informal sector we have taken informal sector employment to be a function of the formal sector employment in various activities, presuming that the expansion in the formal sector leads to rising demand for informal sector activities and employment. In the next step we try to gauge the difference between the level of informal sector employment that is explainable by the formal sector employment and the actual or observed level of informal sector employment. If the latter is much greater than the former it would mean that the supply-push component within the informal sector is very large. The estimation is done in a stochastic frontier function framework (see appendix). The log of informal sector employment is regressed on the log of various components of the formal sector employment in frontier function framework, assuming that the error term follows a one-sided distribution (half-normal distribution in our case). The frontier model has been estimated by Maximum Likelihood Estimation technique and the state Mizoram for the year 1999-2000 reveals the maximum supplies of labour in the informal sector which cannot be explained by the formal sector. Assigning a value of 100 to Mizoram (1999-2000), the other states are indexed accordingly (Table 4). It may be noted that many states which had a low index value in the year 1999-2000 reported a much higher figure for the year 2004-05, indicating that the supply-push component within the informal sector is growing widely across many states. This poses a serious concern because expansion within the informal sector without adequate demand may not engage workers productively and offer wages that comply with the standards of decent employment. In other words, the informal sector is increasingly absorbing labour residually. 


\begin{tabular}{|c|c|c|}
\hline State & $1999-2000$ & $2004-05$ \\
\hline Andhra Pradesh & 53.5 & 94.4 \\
\hline Arunachal Pradesh & 20.1 & 50.9 \\
\hline Assam & 56.5 & 80.1 \\
\hline Bihar \& Jharkhand & 44.1 & 89.1 \\
\hline Goa & 43.4 & 69.4 \\
\hline Gujarat & 47.2 & 85.8 \\
\hline Haryana & 48.8 & 78.0 \\
\hline Himachal Pradesh & 47.1 & 51.9 \\
\hline Jammu and Kashmir & 71.8 & 87.7 \\
\hline Karnataka & 52.7 & 92.8 \\
\hline Kerala & 70.2 & 86.4 \\
\hline Madhya Pradesh and Chhattisgarh & 43.3 & 70.6 \\
\hline Maharashtra & 34.7 & 67.9 \\
\hline Manipur & 83.5 & 77.3 \\
\hline Meghalaya & 61.3 & \\
\hline Mizoram & 100 & 92.7 \\
\hline Nagaland & 39.1 & 63.5 \\
\hline Orissa & 59.9 & 93.2 \\
\hline Punjab & 62.7 & 89.3 \\
\hline Rajasthan & 69.4 & 99.7 \\
\hline Sikkim & 67.1 & 83.8 \\
\hline Tamil Nadu & 53.0 & 90.1 \\
\hline Tripura & 73.4 & 68.1 \\
\hline Uttar Pradesh and Uttaranchal & 65.5 & 90.6 \\
\hline West Bengal & 62.5 & 88.1 \\
\hline Andaman & 39.5 & 60.5 \\
\hline Chandigarh & 73.8 & 79.1 \\
\hline Daman & 75.6 & 82.8 \\
\hline Delhi & 54.6 & 65.5 \\
\hline Lakshadweep & 14.2 & 81.2 \\
\hline Pondicherry & 87.1 & 94.0 \\
\hline
\end{tabular}

Note: Based on the pooled data for two years.

Source: See Maiti and Mitra ${ }^{[0]}$ based on National Sample Survey, 1999-2000 and 2004-05 data

\section{Conclusion}

A sizeable percentage of the workers are engaged in the informal sector both in the rural and urban areas. The component within the informal sector not explainable by the formal sector is vast and it is on the rise over time.The heterogeneity within the informal sector also poses concern because most of the policy initiatives for micro enterprises apply to the manufacturing segment, excluding the vast stretches of unorganized trade and services enterprises. Evidence does not support the view that with increased business subcontracting from the formal sector the informal sector enterprises can benefit either in terms of employment or productivity/wages. Hence, the effects of the growth strategy seem to be narrow and the lack of percolation effects areprevalent. While modernisation and productivity enhancement initiatives for the informal sector may be useful, the supportive policies can reduce the scope of exploitation of the informal sector units by the intermediaries and the formal sector enterprises.

Rural and urban poverty are connected through migration, informal sector employment and other state specific characteristics, though migration and an increased urbanisation tend to reduce both rural and urban poverty. These patterns are, however, quite mild in nature suggesting that the beneficial effects of migration and urbanisation in terms of poverty reduction are not widely prevalent.To make urbanisation more generative greater policy interventions will be required and better support system need to be provided to the migrants, especially in large cities. On the whole, the concept of informal helps us analyse the development dynamics, particularly in relation to urbanisation and urban labour market configurations though it is also noted that over time the informalisation within the formal sector is on the rise which renders the dualistic structure less meaningful.

The efforts on the part of the Indian government to revive industry as the engine of growth may not bring in major changes in the informal/unorganized manufacturing enterprises which are surviving at the margin. The spill-over effects from the organized to the unorganized sector look rather dim. All this creates strong ground for the introduction of informal 
sector policy which may contribute to the wellbeing of the labour employed at the lower rungs. It may identify and facilitate the prime requirements for making this sector vibrant with generation of decent jobs.

\section{Aknowledgement}

There is no conflict of interest.

The author is grateful to Prof. Veena Naregal and two referees of this journal for their constructive comments in the light of which the paper was revised substantially.

\section{Appendix}

A. Factor Analysis

In factor analysis an attempt is made to reduce the dimensions, i.e., to examine if a number of variables can be linearly combined. Each factor is taken to be a linear combination of a group of variables:

$F(j)=\operatorname{sigma} B(i j) X(i)+e(j)$

$\mathrm{j}=1 \ldots \mathrm{k}$, and $\mathrm{i}=1 \ldots . \mathrm{n}$

Where $\mathrm{F}$ is the factor, $\mathrm{X}(\mathrm{i})$ is the ith variable and $\mathrm{B}(\mathrm{ij})$ is the factor loading corresponding to the variable $\mathrm{X}(\mathrm{i})$ in the $\mathrm{jth}$ factor and e a random error. It resembles the multiple regression model but the basic difference between them is that the factors are unobservable whereas in a multiple regression model both the dependent and independent variables have observations. The number of factors $(\mathrm{k})$ chosen is usually less than the number of variables $(\mathrm{i}=1.2 \ldots \mathrm{n})$ under consideration. In other words, only the significant factors i.e., the factors with eigen values or latent roots greater than 1, are taken into consideration. Eigen value is computed as the sum of the square of the factor loadings of all the variables on a given factor. It measures the amount of variation captured by a factor. The proportion of the eigen value of a given factor to the sum of all the eigen values of the factors with positive eigen values gives the percentage of total variation captured. The factor analysis enables to visualize the co-movement of a group of variables. The magnitude of the factor loadings or the coefficient of a variable in a factor can vary between 0 and unity with a positive or negative sign. Variables with coefficients closer to unity (plus or minus) are said to be statistically significant while those closer to 0 are insignificant. The signs of the coefficient of the variables indicate the nature of relationship among them. If one variable takes a positive and another a negative coefficient, it means that both the variables are inversely related. On the other hand, if both the variables have either positive or negative factor loadings, the variables are seen to be moving in the same direction.

B. The stochastic frontier model to estimate the excess growth of the informal sector employment is given by:

$\inf _{i}=F(.) \exp \left(U_{i}+V_{i}\right)$

Where, the non-negative error (Ui) measures the distance between the level of informal sector employment explainable by the formal sector employment and the observed values of informal sector employment. Vi represents the random error. Ui is the extent of supply-push component within the informal sector.

The frontier level informal sector employment is defined as follows:

$\inf _{i}^{*}=F(.) \exp \left(V_{i}\right) \quad$.

The supply push component of the informal sector employment can be measured by the ratio of the observed level of informal sector employment to the frontier level of informal sector employment.

$\operatorname{Einf}_{i}=\inf _{i} / \inf _{i}^{*}=F(.) \exp \left(U_{i}+V_{i}\right) / F(.) \exp \left(V_{i}\right)=\exp \left(U_{i}\right)$ 


\section{References}

[1] Barnes, Tom. Informal Labour in Urban India: Three Cities, Three Journeys. London and New York: Routledge; 2007.

[2] Charmes. J. The Informal Economy Worldwide: Trends and Characteristics. Margin - The Journal of Applied Economic Research. 2012; 6(2): 103-132.

[3] Chen, M. A. Rethinking the Informal Economy: Linkages with the Formal Economy and the Formal Regulatory Environment. DESA Working Paper. 2007; 46.

[4] Dandekar, V. M., Rath, N. Urban poverty in India. Pune: Indian School of Political Economy; 1971.

[5] Das, K. (ed.) Micro and Small Enterprises in India: The Era of Reforms, Routledge. New Delhi.

[6] Goldar, B., Arup Mitra, Anita Kumari. Performance of Unorganised Manufacturing in the Post-reforms Period. In: K, Das. (ed.) Micro and Small Enterprises in India: The Era of Reforms. Routledge, New Delhi: 67-97.

[7] International Labour Office. The Dilemma of the Informal Sector, Report of the Director General (Part-I). Geneva.78th Session. 1991.

[8] Habib-Mintz, N. To What Extent Can the Informal Economy Concept Adequately Explain the Dynamism of the NonFormal Sector in Developing Countries? 2009. https://www.researchgate.net/scientific-contributions/2029167527_ Nazia_Habib-Mintz.

[9] Kucera, D., L. Roncolato. Informal Employment: Two Contested Policy Issues. International Labour Review. 2008; 147: 4.

[10] Maiti, D., Arup Mitra. Skills, Informality and Development. IEG Working Paper. 2010; 306.

[11] Mitra, Arup. Urbanisation, Slums, Informal Sector Employment and Poverty: An Exploratory Study. B.R. Publishing Corporation, Delhi; 1994.

[12] Mitra, Arup. Women in the Informal Sector: Perpetuation of Meagre Earnings. Development and Change. $2005 ; 36 .: 2$.

[13] Mitra, Arup. Migration, Livelihood and Well-being: Evidence from Indian City-Slums. Urban Studies. $2010 ; 47: 7$.

[14] Mitra, Arup. Insights into Inclusive Growth, Employment and Wellbeing in India. Springer. New Delhi. 2013.

[15] Mitra, Arup, Aviral Pandey. Unorganized Sector in India: Employment, Elasticity and Wage-Productivity Nexus,. Journal of Development Entrepreneurship. 2014; 18 (4).

[16] Mukim, Megha. Coagglomeration of formal and informal industry: evidence from India. Journal of Economic Geography. 2015; 15(2): 329-351.

[17] Papola, T.S. Urban Informal Sector in a Developing Economy. Vikas Publishing House; 1981.

[18] Peattie, Lisa. An Idea in Good Currency and How it Grew: The Informal Sector. World Development. $1987 ; 15: 7$.

[19] Rakshit, M. Services-led growth: The Indian experience. Money and Finance. 2007; 3: 91-126.

[20] Sastry, N.S. Estimating Informal Employment and Poverty in India. New Delhi: Human Development Resource Centre, UNDP; 2004.

[21] Srivastava, Ravi. Changing Employment Conditions of the Indian Workforce and Implications for Decent Work. Global Labor Journal. 2012; 3(1): pp. 63-90.

[22] Todaro, M. P. A model of labour migration and urban unemployment in less developed countries. The American Economic Review. 1969; (1): 138-148.

[23] Tendulkar, S. D. Organisedlabour market in India: Pre and post reform. Paper Presented at the Conference on Anti Poverty and Social Policy in India: Alwar; 2004. 